\title{
Hepatocyte Concentrations of Imaging Compounds Associated with Transporter Inhibition: Evidence in Perfused Rat Livers
}

\author{
Pierre Bonnaventure, Fabien Cusin, and $\odot$ Catherine M. Pastor
}

Department of Radiology, Hôpitaux Universitaires de Genève, Geneva, Switzerland (P.B., F.C., C.M.P.); and Laboratory of Imaging Biomarkers, Centre of Research on Inflammation, Unité Mixte de Recherche 1149, Institut National de la santé et de la Recherche Médicale and University Paris Diderot, Paris, France (C.M.P.)

Received September 21, 2018; accepted January 18, 2019

\begin{abstract}
In the liver, several approaches are used to investigate and predict the complex issue of drug-induced transporter inhibition. These approaches include in vitro assays and pharmacokinetic models that predict how inhibitors modify the systemic and liver concentrations of the victim drugs. Imaging is another approach that shows how inhibitors might alter liver concentrations stronger than systemic concentrations. In perfused rat livers associated with a gamma counter that measures liver concentrations continuously, we previously showed how fluxes across transporters generate the hepatocyte concentrations of two clinical imaging compounds, one with a low extraction ratio [gadobenate dimeglumine (BOPTA)] and one with a high extraction ratio [mebrofenin (MEB)]. BOPTA and MEB are transported by rat organic anion transporting polypeptide and multiple resistance-associated protein 2 , which are
\end{abstract}

both inhibited by rifampicin. The aim of the study is to measure how rifampicin modifies the hepatocyte concentrations and membrane clearances of BOPTA and MEB and to determine whether these compounds might be used to investigate transporter-mediated drug-drug interactions in clinical studies. We show that rifampicin coperfusion greatly decreases BOPTA hepatocyte concentrations, but increases those of MEB. Rifampicin strongly decreases BOPTA hepatic clearance. In contrast, rifampicin decreases moderately MEB hepatic clearance and blocks the biliary intrinsic clearance, increasing MEB hepatocyte concentrations. In conclusion, low concentrations prevent the quantification of BOPTA biliary intrinsic clearance, while MEB is a promising imaging probe substrate to evidence transporter-mediated drug-drug interactions when inhibitors act on influx and efflux transporters.

\section{Introduction}

Several approaches are used to investigate and predict the complex issue of drug-induced transporter inhibition. The topic is widely described in in vitro assays, but the translational information to patients is questioned because the inhibition is mainly tested with prototypical and not clinically relevant substrates (Belzer et al., 2013; Martínez-Guerrero and Wright, 2013; Izumi et al., 2015; Pedersen et al., 2017; Koide et al., 2018). In the liver, several pharmacokinetic models describe how transporter inhibition modifies the drug clearances (CLs) across these transporters to explain and predict the modified systemic concentrations induced by inhibitors (Watanabe et al., 2010; Yoshida et al., 2012; Patilea-Vrana and Unadkat, 2016, 2018; Benet et al., 2018a,b). Another approach of drug-induced transporter inhibition relies on liver imaging (Langer, 2016; Tournier et al., 2018). Liver imaging estimates concentrations that should be high enough for drugs targeting hepatocytes but low enough to avoid cell injury when the target is extrahepatic (Chu et al., 2013; Dollery, 2013;

This work was supported by the Swiss National Foundation [Grant 126030]. https://doi.org/10.1124/dmd.118.084624.
Guo et al., 2018). Pharmacokinetic models of liver images acquired over time estimate transfer rates and CLs between two compartments of the liver, as well as liver area under the curve (AUC) (Ali et al., 2018; Bauer et al., 2018a; Caillé et al., 2018; Kaneko et al., 2018; Leporq et al., 2018). Some of these studies suggest that liver concentrations might be more altered than systemic concentrations when inhibitors such as rifampicin (RIF) are concomitantly substrates of uptake transporters and decrease bile excretion rates $\left(\mathrm{v}_{\text {bile }}\right)$ (PatileaVrana and Unadkat, 2016, 2018; Benet et al., 2018a; Kaneko et al., 2018). To detect transporter-mediated drug-drug interactions, imaging analyzes whether a potential inhibitor modifies the liver distribution of a transporter-specific tracer or magnetic resonance contrast agent (Langer, 2016). These compounds are designated usually as imaging probe substrates.

In perfused rat livers, we demonstrated previously how drug influx and efflux across membrane transporters generate the hepatocyte concentrations of two hepatobiliary compounds used in clinical imaging: gadobenate dimeglumine (BOPTA; MultiHance; Bracco Imaging, Milan, Italy) for magnetic resonance imaging (Daali et al., 2013) and ${ }^{99 \mathrm{~m}} \mathrm{Tc}$-mebrofenin (MEB; Choletec; Bracco Imaging) for single photon

ABBREVIATIONS: ANOVA, analysis of variance; AUC, area under the curve; $\mathrm{AUC}_{\mathrm{HC}}$, area under the curve of hepatocyte concentration; $\mathrm{AUCR}$, area under the curve ratio; BOPTA, gadobenate dimeglumine; $\mathrm{C}_{\text {bile, }}$, drug concentration measured in the common bile duct; $\mathrm{C}_{\mathrm{bile}}, 75 \mathrm{~min}$, drug concentration measured in the common bile duct at 75 minutes; $\mathrm{C}_{\mathrm{HC}}$, hepatocyte concentration; $\mathrm{C}_{\mathrm{HC}, 75 \mathrm{~min}}$, hepatocyte concentration at 75 minutes; $\mathrm{C}_{\text {in }}$, constant concentration entering the liver via the portal vein; $C L$, clearance; $\mathrm{CL}_{\text {ef }}$, Efflux clearance; $\mathrm{CL}_{\text {in }}$, basolateral influx clearance; $\mathrm{CL}_{\text {int,bil }}$, biliary intrinsic clearance; $\mathrm{C}_{\mathrm{Mrp3}}$, drug concentration generated by efflux through Mrp3; $\mathrm{C}_{\text {out }}$, measured concentrations in hepatic veins; DTPA, gadopentetate dimeglumine; $\mathrm{f}_{\mathrm{B}}$, unbound fraction of drugs in blood; $\mathrm{f}_{\mathrm{L}}$, unbound drug fraction in liver; HV, hepatic vein; KHB, Krebs-Henseleitbicarbonate; MEB, mebrofenin; Mrp, multiple resistance-associated protein; Oatp, organic anion transporting polypeptide; $Q_{b i l e}$, bile flow rate; $Q_{H}$, liver flow rate; RIF, rifampicin; SPECT, single photon emission computed tomography; $v$, removal rate of drug from sinusoids; $v_{b i l e}$, bile excretion rate; $v_{\text {ef, }}$ basolateral efflux out of hepatocytes. 
emission computed tomography imaging (Bonnaventure and Pastor, 2014). This experimental model was original because we placed a gamma counter over a liver lobe that continuously measures the liver concentrations of both compounds. Hepatocyte concentrations can then be calculated easily by knowing the extracellular and biliary concentrations. BOPTA (Planchamp et al., 2007; Millet et al., 2011) and MEB (Ghibellini et al., 2008; de Graaf et al., 2011; Neyt et al., 2013) enter into hepatocytes through the organic anion transporting polypeptides (Oatps) and efflux from cells back to sinusoids via the multiple resistance-associated protein $3(\mathrm{Mrp} 3)$ and into bile canaliculi via the Mrp2 (Ghibellini et al., 2008; Millet et al., 2011) (Fig. 1). The biliary excretion rates of MEB measured in sandwich-cultured hepatocytes from rats lacking Mrp2 is negligible (Swift et al., 2010), and mice deficient in Mrp2 transporter do not excrete MEB into bile canaliculi (Neyt et al., 2013). BOPTA and MEB are not metabolized in hepatocytes, and their hepatic pharmacokinetics are different because BOPTA has a low liver extraction ratio, while that of MEB is very high. With the same experimental model, we quantified the hepatic distribution of the transporter inhibitor RIF. When $100 \mu \mathrm{M}$ RIF was perfused in rat livers, its hepatic CL into hepatocytes at steady state was $5 \mathrm{ml} / \mathrm{min}$ and its extraction ratio was $17 \%$ (Daali et al., 2013). In this study, we quantified the liver concentrations of RIF by obtaining serial biopsy samples along the perfusion protocol. The maximal liver concentrations were $668 \pm 93 \mu \mathrm{M}$. RIF is a substrate (Tirona et al., 2003) and inhibitor of rat and human OATPS (Tirona et al., 2003; Karlgren et al., 2012). The transport of RIF across Mrp2 was not investigated, but we showed that the RIF $v_{\text {bile }}$ values are negligible in normal rats compared with its high basolateral efflux back to sinusoids (Daali et al., 2013).

The aim of the study was to measure how RIF modifies the hepatocyte concentrations and membrane CLs of BOPTA and MEB in our model, which includes continuous measurements of liver concentrations, and to determine whether these compounds might be useful to investigate transporter-mediated drug-drug interactions in clinical studies.

\section{- BOPTA or MEB \\ - Rifampicin}

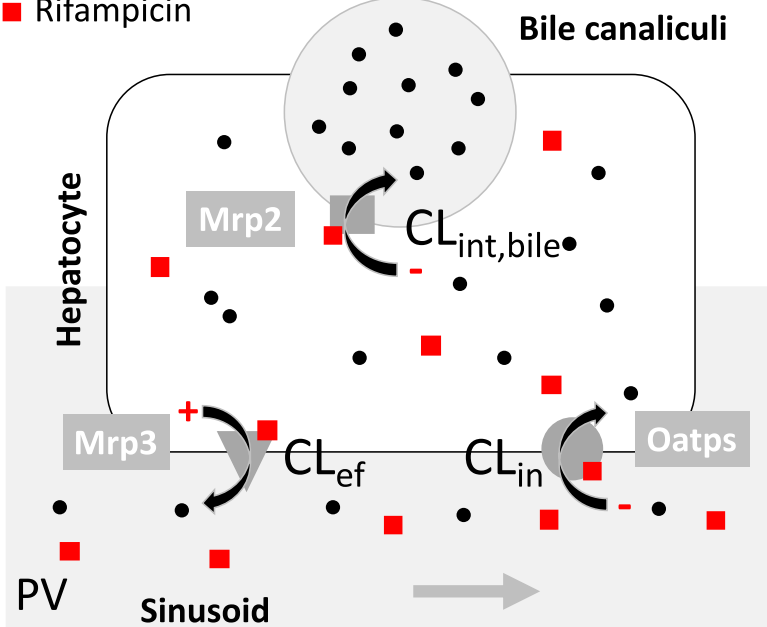

HV

Fig. 1. BOPTA and MEB transport across hepatocyte membranes and concentrations inside liver compartments. BOPTA and MEB distribute into sinusoids and interstitium before entry into normal hepatocytes across Oatps. Once inside hepatocytes, both compounds exit into bile canaliculi across the Mrp2 or back into sinusoids

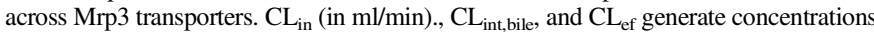
that increase from sinusoids, to hepatocytes and bile canaliculi (illustrated by the number of circles). RIF is a substrate of Oatps and inhibits both Oatps and Mrp2. $\mathrm{HV}$, hepatic vein; PV, portal vein.

\section{Materials and Methods}

Animals. Before liver isolation, male Sprague-Dawley rats $(n=19)$ were anesthetized with pentobarbital $\left(50 \mathrm{mg} \cdot \mathrm{kg}^{-1}\right.$, i.p.). The protocol was carried out in accordance with the Swiss Guidelines for the Care and Use of Laboratory Animals and was approved by the local animal welfare committee and the veterinary office in Geneva, Switzerland. We previously perfused three rats with BOPTA and RIF, and for this group we reanalyzed the raw data to calculate the CL parameters (Daali et al., 2013).

Isolated Perfused Rat Livers. We isolated and perfused the rat livers, as published recently (Bonnaventure and Pastor, 2014; Daire et al., 2017). The rat livers were isolated leaving organs in the carcass. The abdominal cavity was opened, and the portal vein was cannulated (16-gauge catheter). The hepatic artery was not perfused. The abdominal vena cava was transected, and an oxygenated Krebs-Henseleit-bicarbonate (KHB) solution $(118 \mathrm{mM}$ $\mathrm{NaCl}, 1.2 \mathrm{mM} \mathrm{MgSO}_{4}, 1.2 \mathrm{mM} \mathrm{KH}_{2} \mathrm{PO}_{4}, 4.7 \mathrm{mM} \mathrm{KCl}, 26 \mathrm{mM} \mathrm{NaHCO}_{3}$, and $2.5 \mathrm{mM} \mathrm{CaCl}_{2}$ ) was pumped without delay into the portal vein, the solution being discarded after liver distribution by a vena cava transection. The flow rate was slowly increased over 1 minute up to $30 \mathrm{ml} / \mathrm{min}$ to prevent injury of sinusoidal cells. In a second step, the chest was opened and a cannula (14 gauge) was inserted through the right atrium to collect solutions flowing from hepatic veins (HVs). Finally, the abdominal inferior vena cava was ligated, allowing the KHB solutions perfused by the portal vein to be eliminated by the HVs.

The perfusion system included a reservoir, a pump, a heating circulator, a bubble trap, a filter, and an oxygenator. Solutions of perfusion were equilibrated with a mixture of $95 \% \mathrm{O}_{2}-5 \% \mathrm{CO}_{2}$. The livers were perfused with the $\mathrm{KHB}$ buffer with or without drugs using a nonrecirculating system, with livers always being perfused by fresh solutions. In each liver, the common bile duct was cannulated with a $\mathrm{PE}_{10}$ catheter, and bile samples were collected every 5 minutes to measure bile flow rates (in microliters per minute per liver) and BOPTA and MEB concentrations (micromolar). Samples were also collected from the HVs every 5 minutes to measure BOPTA and MEB concentrations (micromolar).

Drug Perfusion. Rat livers were perfused with either gadopentetate dimeglumine (DTPA; Magnevist; Bayer, Berlin, Germany) and BOPTA (MultiHance; Bracco Imaging) or Technescan DTPA (b.e.imaging GmbH, Schwyz, Switzerland) (DTPA) and MEB (Choletec; Bracco Imaging). DTPA distributes within the sinusoids and the interstitium, while BOPTA and MEB enter into hepatocytes before excretion into bile canaliculi. In the first group of rats, ${ }^{153} \mathrm{Gd}$-DTPA and ${ }^{153} \mathrm{Gd}$-BOPTA were obtained by adding ${ }^{153} \mathrm{GdCl}_{3}(1 \mathrm{MBq} / \mathrm{ml})$ to the commercially available $0.5 \mathrm{M}$ solutions of DTPA and BOPTA. In the second group of rats, $25 \mathrm{mg}$ of DTPA and MEB were labeled with ${ }^{99 \mathrm{~m}} \mathrm{Tc}$ (7 and $11 \mathrm{MBq}$, respectively). Then, ${ }^{153} \mathrm{Gd}$-DTPA and ${ }^{153} \mathrm{Gd}$-BOPTA were diluted in the KHB solutions to obtain $200 \mu \mathrm{M}$ concentrations, while ${ }^{99 \mathrm{~m}} \mathrm{Tc}-\mathrm{DTPA}$ and ${ }^{99 \mathrm{~m}} \mathrm{Tc}-\mathrm{MEB}$ were diluted to obtain $64 \mu \mathrm{M}$ concentrations. The livers were successively perfused with $200 \mu \mathrm{M}{ }^{153}$ Gd-DTPA (10 minutes), KHB solution (35 minutes), $200 \mu \mathrm{M}{ }^{153} \mathrm{Gd}-\mathrm{BOPTA}$ (perfusion period, 30 minutes), and $\mathrm{KHB}$ solution (rinse period, 30 minutes); or with $64 \mu \mathrm{M}{ }^{99 \mathrm{~m}} \mathrm{Tc}-\mathrm{DTPA}$ (10 minutes), KHB solution (35 minutes), $64 \mu \mathrm{M}^{99 \mathrm{~m}} \mathrm{Tc}-\mathrm{MEB}$ (perfusion period, 30 minutes), and KHB solution (rinse period, 30 minutes). Thus, the following two periods are distinguished: 1) a perfusion period that shows drug accumulation in liver compartments and 2) a rinse period that investigates drug hepatocyte effluxes into bile canaliculi and back to sinusoids. The maximal perfusion period for each experiment was 105 minutes. DTPA is perfused to calculate the BOPTA and MEB hepatocyte concentrations (see the following section).

Rats were perfused with $200 \mu \mathrm{M} \mathrm{BOPTA}(n=6)$ or $64 \mu \mathrm{M} \mathrm{MEB}(n=6)$ during the perfusion period. In two additional groups, BOPTA and MEB perfusion were associated with RIF $(100 \mu \mathrm{M})$ : BOPTA+RIF $(n=3)$ and $\operatorname{MEB}+\operatorname{RIF}(n=4)$ groups. RIF was not perfused during the rinse period.

Quantification of Drug Concentrations over Time in Liver Compartments. To quantify the liver concentrations, a gamma counter that measured count rates every 20 seconds was placed $1 \mathrm{~cm}$ above a liver lobe. The counter measured the radioactivity in a region of interest that was identical in each experiment. To transform the count rates into drug concentrations, the total liver radioactivity was measured by an activimeter (Isomed 2000; Canberra, Saint-Quentin-en-Yvelines, France) at the end of each experiment and was related to the last count rates. DTPA, BOPTA, and MEB concentrations in common bile duct and HVs were measured every 5 minutes with a gamma counter (Canberra). In great vessels, bile ducts, and livers, micromolar 
concentrations are expressed. We considered that $1 \mathrm{~g}$ of liver was close to $1 \mathrm{ml}$. All concentrations measured in solutions or livers ranged within standard values. Bile samples were diluted.

Calculation of Hepatocyte Drug Concentrations. In the region of interest, the drug liver concentrations were the sum of the concentrations in the extracellular space, bile canaliculi, and hepatocytes. The concentrations of the extracellular space were assessed during DTPA perfusion. The concentrations in the bile canaliculi measured by the counter were calculated by multiplying the bile concentrations in the common bile duct by the volume of bile canaliculi (percentage) in the rat liver. Blouin et al. (1977) previously estimated this volume at $0.43 \%$. We also assumed that the drug concentrations were similar in the bile canaliculi and the common bile duct, although solute export from the cholangiocytes and water transport along ductules and ducts may modify the primary bile composition. The drug hepatocyte concentrations were calculated by subtracting the DTPA and bile canaliculi concentrations from the liver concentrations. Finally, because drug concentrations measured by the counter originated from a $78 \%$ volume of hepatocytes (Blouin et al., 1977), we increased the calculated values to $100 \%$ to obtain the true concentrations in the hepatocyte volume.

Drug Influx into Hepatocytes. The net removal rate of drug from sinusoids [ $\mathrm{v}$ (in nanomoles per minute)] were measured by $\mathrm{Q}_{\mathrm{H}}\left(\mathrm{C}_{\mathrm{in}}-\mathrm{C}_{\mathrm{out}}\right)$, where $\mathrm{Q}_{\mathrm{H}}$ is the liver flow rate $(30 \mathrm{ml} / \mathrm{min}$ in all experiments $), \mathrm{C}_{\text {in }}$ is the constant concentrations entering the liver via the portal vein, and $\mathrm{C}_{\text {out }}$ is the measured concentrations in HVs. The unbound fraction of drugs in blood $\left(f_{B}\right)$ was 1 because no protein is added into the perfusate and $C_{i n}$ and $C_{\text {out }}$ are similar to $f_{B} C_{\text {in }}$ and $f_{B} C_{\text {out }}$. The hepatic CL (in milliliters per minute) is the ratio of $\mathrm{v}$ and $\mathrm{C}_{\mathrm{in}}$. The drug liver extraction ratio $(\mathrm{E})$ is $\left(\mathrm{C}_{\mathrm{in}}-\mathrm{C}_{\text {out }}\right) / \mathrm{C}_{\mathrm{in}}$.

Using the counter placed over the liver, the hepatocyte uptake into hepatocytes (in micromoles per minute) was measured by the slope of the relation between hepatocyte concentrations and time over 2 minutes at the very beginning of the drug perfusion to avoid an underestimation of hepatocyte concentrations associated with early excretion into bile canaliculi. A delay of 1 minute (from 45 to 46 minutes) assured a homogeneous drug distribution within the interstitium.

Drug Efflux from Hepatocytes. The biliary excretion rate $\left[\mathrm{v}_{\mathrm{bile}}\right.$ (in nanomoles per minute)] was calculated by $\mathrm{C}_{\text {bile }} \cdot$ bile flow rate $\left(\mathrm{Q}_{\text {bile }}\right)$, where $\mathrm{C}_{\text {bile }}$ is the drug concentration measured in the common bile duct. The biliary intrinsic $C L\left[\mathrm{f}_{\mathrm{L}} \mathrm{CL}_{\text {int,bile }}\right.$ (in milliliters per minute)] was the ratio of $\mathrm{v}_{\text {bile }}$ and hepatocyte concentration $\left[\mathrm{C}_{\mathrm{HC}}\right.$ (in nanomoles per gram or micromolar)], and the unbound drug fraction in liver is $\mathrm{f}_{\mathrm{L}} \cdot \mathrm{v}_{\text {bile }}$ and $\mathrm{f}_{\mathrm{L}} \mathrm{CL}_{\mathrm{int}}$,bile were measured every 5 minutes. The basolateral efflux out of hepatocytes $\left[\mathrm{v}_{\mathrm{ef}}\right.$ (in nanomoles per minute)] was calculated by $\mathrm{C}_{\mathrm{out}} \cdot \mathrm{Q}_{\mathrm{H}}$, and the basolateral efflux CL $\left[\mathrm{f}_{\mathrm{L}} \mathrm{CL}_{\mathrm{ef}}\right.$ (in milliliters per minute)] is $\mathrm{v}_{\mathrm{ef}}$ divided by $\mathrm{C}_{\mathrm{HC}}$. To calculate the partition of drug efflux into bile canaliculi and sinusoids, we measured the ratio of the AUCs of $v_{\text {bile }}$ and $v_{e f}$ from 85 to 105 minutes. $v_{\text {ef }}$ is not available during the perfusion period because, in HVs, we cannot distinguish between the drugs that returned from hepatocytes into sinusoids from those that never entered into hepatocytes. However, knowing $\mathrm{f}_{\mathrm{L}} \mathrm{CL}_{\mathrm{ef}}$, we can extrapolate drug concentrations that efflux through $\operatorname{Mrp} 3\left(\mathrm{C}_{\mathrm{Mrp} 3}\right)$ at the end of the perfusion period (T75 minutes): $\mathrm{C}_{\mathrm{Mpr} 3,75 \min }=\mathrm{f}_{\mathrm{L}} \mathrm{CL}_{\mathrm{ef}} \cdot \mathrm{C}_{\mathrm{HC}, 75 \mathrm{~min}} / \mathrm{Q}_{\mathrm{H}}$. We can then calculate the basolateral influx $C L\left(f_{L} C L_{\text {in }}\right.$ at $75 \min =\left(C_{\text {in }}-C_{\text {out }}-C_{M r p 3,75 m i n}\right) Q_{H} / C_{i n}$.

Inhibition Potency of RIF on Systemic and Hepatocyte MEB and BOPTA Concentrations. To better quantify the inhibition potency of RIF on systemic and hepatocyte drug concentrations, we calculated the AUC of hepatocyte concentrations from 45 to 105 minutes $\left(\mathrm{AUC}_{\mathrm{HC}, 45-105}\right)$ and $\mathrm{AUC}$ of $\mathrm{C}_{\text {out }}$ from 45 to 75 minutes $\left(\mathrm{AUC}_{\mathrm{Cout}, 45-75}\right)$ in the four experimental groups and determined the following $\mathrm{AUC}$ ratios (AUCRs): $\mathrm{AUCR}_{\mathrm{HC},+\mathrm{RIF} /-\mathrm{RIF}}$ and $\mathrm{AUCR}_{\mathrm{Cout},+\mathrm{RIF} / \mathrm{RIF}}$. Indeed, the systemic concentrations in vivo vary in accordance to $\mathrm{C}_{\text {out }}$ modifications.

Viability of Liver Perfusion. Liver viability during the experimental period (105 minutes) was assessed by measuring portal pressures and bile flow rates. The portal pressures remained at $<10 \mathrm{mmHg}$ in all rats. In the absence of red blood cells in the perfusate, we (Pastor et al., 1998) and other researchers (Mischinger et al., 1992) used a flow rate of $3 \mathrm{ml} / \mathrm{min}$ per gram liver. With such a flow rate, portal pressures remained steady in the four groups of rats: $4.7 \pm 0.4 \mathrm{mmHg}$ (BOPTA); $5.8 \pm 1.0 \mathrm{mmHg}$ (BOPTA+RIF); $7.7 \pm 1.2 \mathrm{mmHg}(\mathrm{MEB})$; and $8.0 \pm$ $1.0 \mathrm{~mm} \mathrm{Hg}(\mathrm{MEB}+\mathrm{RIF})$. This flow rate delivers enough $\mathrm{O}_{2}$ to maintain a normal liver $\mathrm{O}_{2}$ consumption (Pastor et al., 1998). It also prevents the inhomogeneous distribution of perfused solutions (Bessems et al., 2006).
A steady bile flow is another parameter of liver viability during the experimental protocol. Bile flow rates were measured in the four experimental groups over time (Fig. 2).

Statistics. Parameters are the mean \pm S.D. To compare the evolution of parameters over time in one group, we use a one-way analysis of variance (ANOVA) and to compare parameters over time in several groups, we use a two-way ANOVA with the Sidak's multiple-comparison test of mean values at each time point between groups (Prism 7; GraphPad Software, La Jolla, CA). To analyze the drug uptake rates over time and the relationship between $\mathrm{v}_{\text {bile }}$ and bile concentrations, we used linear regressions.

\section{Results}

Effect of Drugs on Liver Flow Rates. BOPTA is a choleretic drug. Bile flow rates increased during the perfusion and recovered along the rinse period (Fig. 2). MEB perfusion had no effect on bile flow rates, and RIF perfusion slightly decreased the bile flow rates, with a rapid recovery before the end of the protocol. Thus, only BOPTA $\mathrm{v}_{\text {bile }}$ values relied on both increased canalicular fluid transfer and biliary concentrations.

MEB and BOPTA Hepatic Pharmacokinetics and Concentrations. The MEB v value was steady over time $(1797 \pm 61 \mathrm{nmol} / \mathrm{min})$, and the maximal $v_{\text {bile }}$ value reached $990 \pm 166 \mathrm{nmol} / \mathrm{min}$ at the end of the perfusion period (Fig. 3C, right, $y$-axis). The MEB $\mathrm{v}_{\mathrm{ef}}$ from 85 to 105 minutes was measured during the rinse period because during this period MEB $\mathrm{C}_{\text {out }}$ originated only from hepatocytes. The efflux was minimal $(<10 \mathrm{nmol} / \mathrm{min})$. These three fluxes generated an increase in hepatocyte concentrations over time that reached $2611 \pm 98 \mu \mathrm{M}$ (Fig. 3B). The low concentrations in HVs $\left(\mathrm{C}_{\text {out }}\right)$ at $\sim 4 \mu \mathrm{M}$ (Fig. 3A) explained the high extraction ratio of $\mathrm{MEB}(0.93 \pm 0.03)$. The maximal bile concentration was $97,017 \pm 11,289 \mu \mathrm{M}$ (Fig. 3C, left, $y$-axis). During the rinse period, all parameters decreased steadily in the absence of MEB perfusion.

The BOPTA $v$ value was much lower than that of MEB and significantly decreased over time to reach a steady value of $464 \pm$ $80 \mathrm{nmol} / \mathrm{min}$. $\mathrm{C}_{\text {out }}$ values were close to $\mathrm{C}_{\text {in }}$ values (Fig. $4 \mathrm{~A}$ ), and the liver extraction ratio was $0.08 \pm 0.01$. The maximal $\mathrm{v}_{\text {bile }}$ (Fig. $4 \mathrm{C}$, right, $y$-axis) and the bile concentrations (Fig. $4 \mathrm{C}, x$-axis) were lower during BOPTA perfusion compared with MEB perfusion $(P<$ 0.0001). The ratios of $A U C v_{\text {bile }}$ to $A U C v_{\text {ef }}$ from 85 to 105 minutes were 5.3 (BOPTA) and 40.4 (MEB). Thus, MEB basolateral efflux was negligible, and only BOPTA $v_{\text {ef }}$ might increase the $\mathrm{C}_{\text {out }}$ measured in HVs.

MEB hepatic CL over time was steady over the perfusion period $(28.2 \pm 0.9 \mathrm{ml} / \mathrm{min}, P=0.12)$ and much higher than BOPTA $\mathrm{CL}$, which decreased significantly over time to $2.5 \pm 0.1 \mathrm{ml} / \mathrm{min}$

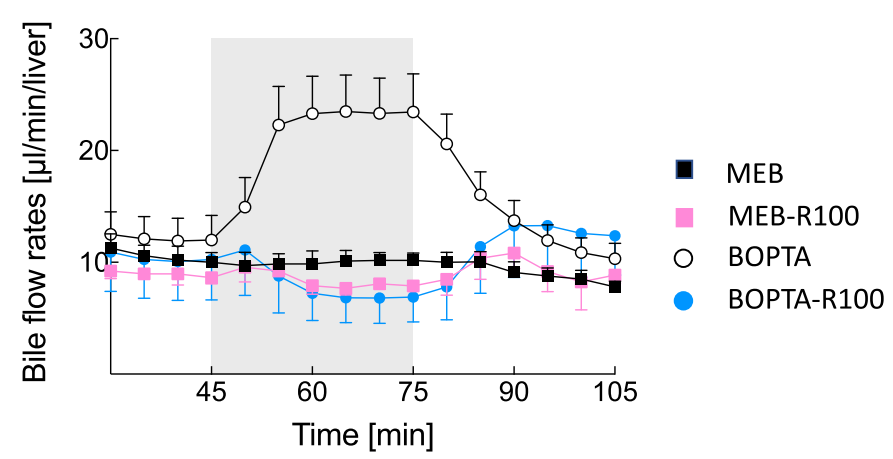

Fig. 2. Effects of drug perfusion on bile flow rates over the experimental protocol (105 minutes). Livers were perfused with $200 \mu \mathrm{M}$ BOPTA (white circles), $64 \mu \mathrm{M}$ MEB (black squares), $200 \mu \mathrm{M}$ BOPTA and $100 \mu \mathrm{M}$ RIF (blue circles), and $64 \mu \mathrm{M}$ MEB and $100 \mu \mathrm{M}$ RIF (pink squares). 
A

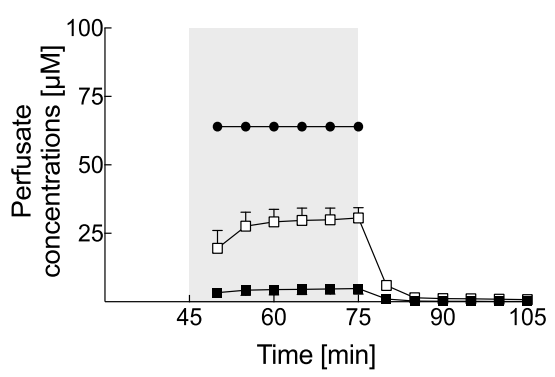

B

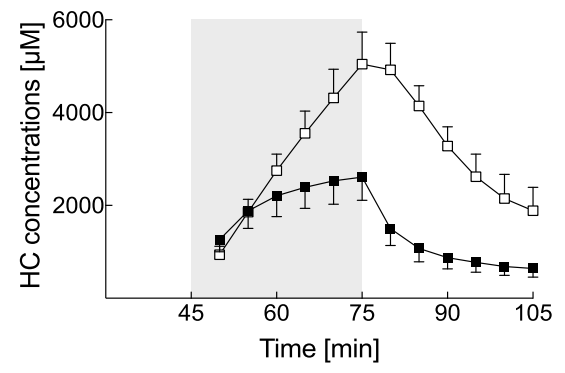

C

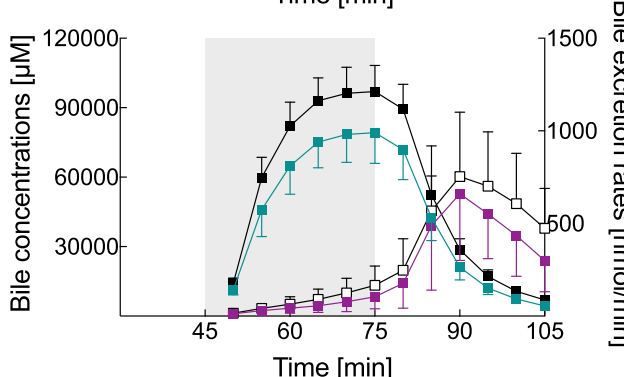

D
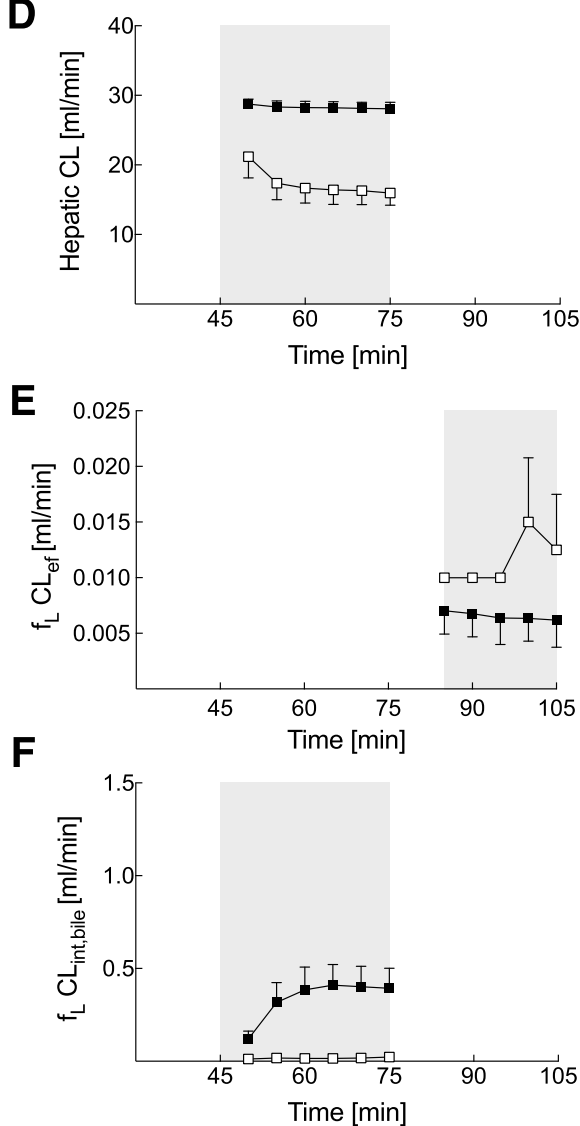

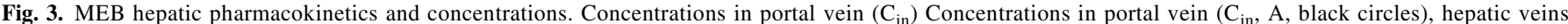

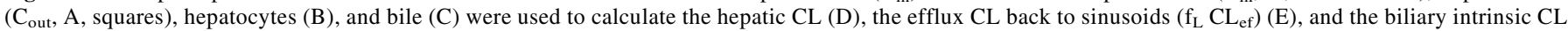

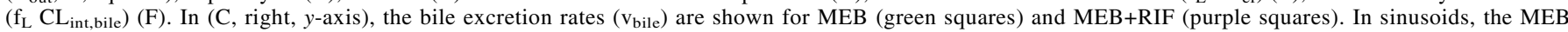

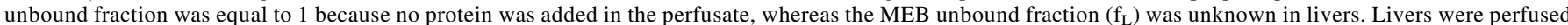

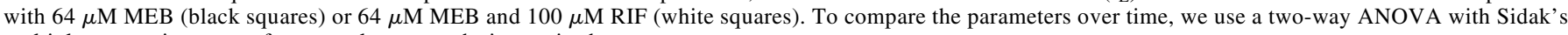
multiple comparison test of mean values at each time point between groups.

$(P=0.04)$ (Fig. 3D; Fig. 4D). BOPTA and MEB $\mathrm{f}_{\mathrm{L}} \mathrm{CL}_{\text {int, bile values }}$ were steady from 55 to 75 minutes (Fig. 3F; Fig. 4F), but values were higher in livers perfused with BOPTA $(0.85 \pm 0.25 \mathrm{ml} / \mathrm{min})$ than in those perfused with MEB $(0.41 \pm 0.11 \mathrm{ml} / \mathrm{min}, P<0.001)$. Another way to assess the $\mathrm{CL}_{\text {int,bile }}$ is to plot $\mathrm{v}_{\text {bile }}$ values and hepatocyte concentrations during the perfusion period (Fig. 5B). The slopes of the linear regressions were not significantly different: $\mathrm{MEB}, 0.31 \pm 0.07 \mathrm{ml} / \mathrm{min}$; BOPTA, $0.66 \pm 0.15 ; P=0.22 . \mathrm{MEB} \mathrm{f}_{\mathrm{L}}$ $\mathrm{CL}_{\mathrm{ef}}$ values represented only $2 \%$ of $\mathrm{f}_{\mathrm{L}} \mathrm{CL}_{\text {int,bile }}$ (Fig. 3, E and F), whereas BOPTA $\mathrm{f}_{\mathrm{L}} \mathrm{CL}_{\mathrm{ef}}$ represented $<15 \%$ of $\mathrm{f}_{\mathrm{L}} \mathrm{CL}_{\text {int,bile }}$ (Fig. 4, E and F). Moreover, BOPTA $\mathrm{f}_{\mathrm{L}} \mathrm{CL}_{\mathrm{ef}}$ values were not steady and decreased along the rinse period. The estimated $\mathrm{C}_{\mathrm{Mrp} 3}$ values at T75 minutes were $2.45 \pm 0.43$ (BOPTA) and $0.88 \pm 0.18 \mu \mathrm{M}$ (MEB). As expected, the $\mathrm{f}_{\mathrm{L}} \mathrm{CL}_{\text {in }}$ value was close to $\mathrm{CL}$ for MEB but higher for BOPTA (Table 1). The $\mathrm{f}_{\mathrm{L}} \mathrm{CL}_{\mathrm{in}} / \mathrm{CL}$ ratios were 1.16 (BOPTA) and 1.01 (MEB).

Two other parameters can be calculated with the experimental model. The hepatocyte uptake into hepatocytes (in micromoles per minute) measured by the slope of the relation between hepatocyte concentrations and time over 2 minutes was significantly higher with MEB than with BOPTA (Fig. 5A) $(P<0.0001)$. The concentrative activity of Mrp2 was estimated by calculating the concentration gradients between $\mathrm{C}_{\mathrm{bile}}$ at 75 minutes $\left(\mathrm{C}_{\mathrm{bile}}, 75 \mathrm{~min}\right)$ and $\mathrm{C}_{\mathrm{HC}}$ at 75 minutes $\left(\mathrm{C}_{\mathrm{HC}, 75 \min }\right)$ (Table 1$)$. Both gradients were similar at 75 minutes $(P=0.92)$.
Effects of Transporter Inhibition by RIF. RIF had very different effects on MEB and BOPTA hepatocyte concentrations. The maximal MEB hepatocyte concentrations were higher in the presence of RIF $(5044 \pm 693$ vs. $2611 \pm 98 \mu \mathrm{M})$, whereas those of BOPTA were much lower $(23 \pm 19$ vs. $566 \pm 99 \mu \mathrm{M})$ (Table 1$)$. Thus, RIF impeded BOPTA entry into hepatocytes, and the hepatocyte uptake from 46 to 48 minutes was only $3 \pm 3 \mu \mathrm{M} / \mathrm{min}$ (Fig. 5A). Consequently, BOPTA hepatocyte concentrations became too low to analyze correctly the inhibitory effect of RIF on Mrp2. MEB hepatocyte uptake was moderately lower in the presence of RIF $(210 \pm 3 \mu \mathrm{M} / \mathrm{min})$ than in the absence of RIF $(296 \pm 1 \mu \mathrm{M} / \mathrm{min})(P<0.0001)$ (Fig. 5A), and the concomitant Mrp2 inhibition by RIF increased MEB hepatocyte concentrations over time.

BOPTA hepatocyte concentrations over time (i.e., $\mathrm{AUC}_{\mathrm{HC}}$ ) found similar results. $\mathrm{AUC}_{\mathrm{HC}}$ values were 18,822 $\pm 3758 \mu$ M.min (BOPTA) and $1174 \pm 440 \mu \mathrm{M} \cdot \min (\mathrm{BOPTA}+\mathrm{RIF})(P=0.02)$ with a ratio of 0.47 . $\mathrm{AUC}_{\mathrm{HC}}$ values were $90,564 \pm 17,933 \mu \mathrm{M}$.min (MEB) and 180,203 $\pm 21,308 \mu$ M.min $(\mathrm{MEB}+\mathrm{RIF})(P=0.01)$ with a ratio of 2 . The higher MEB and BOPTA concentrations in HVs in the presence of the inhibitor confirmed the decreased MEB entry into hepatocytes (Fig. 3A; Fig. 4A) as did $\mathrm{AUC}_{\text {Cout } 45-75}$. The ratio AUCR $_{\text {Cout }}$ was 1.07 with $4503 \pm 71 \mu \mathrm{M} \cdot \min (\mathrm{BOPTA})$ and $4820 \pm$ $38 \mu$ M.min $\left(\right.$ BOPTA+RIF) $(P=0.02)$. MEB AUCR Cout $_{\text {was }} 6.43$ with $110 \pm 47 \mu$ M.min $(\mathrm{MEB})$ and $708 \pm 117 \mu \mathrm{M} \cdot \min (\mathrm{MEB}+\mathrm{RIF})$, $(P=0.01)$. 
A

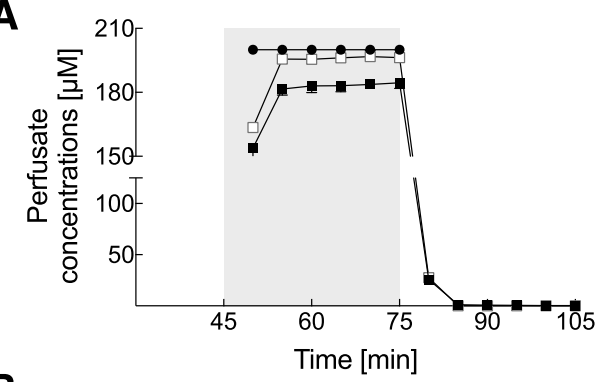

B

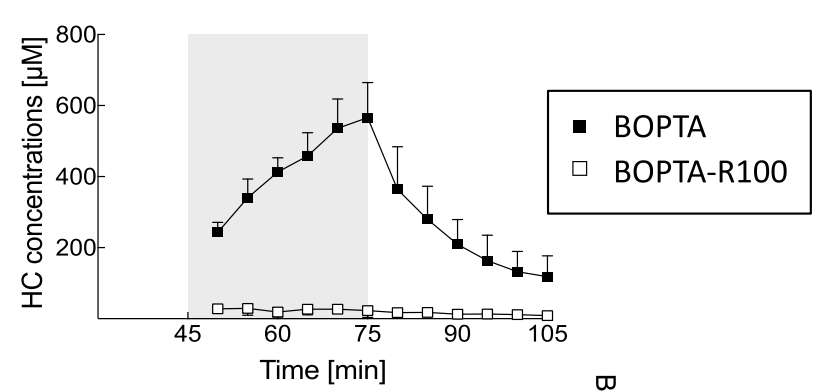

C

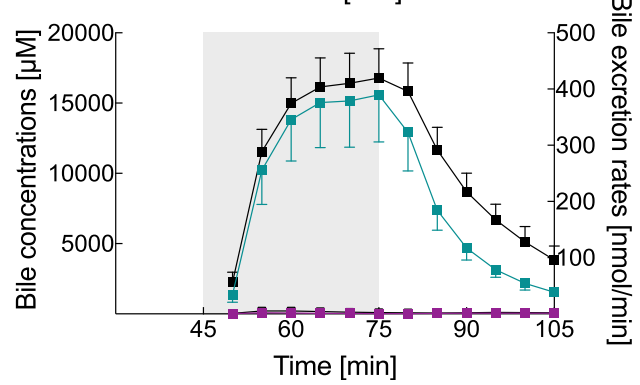

D

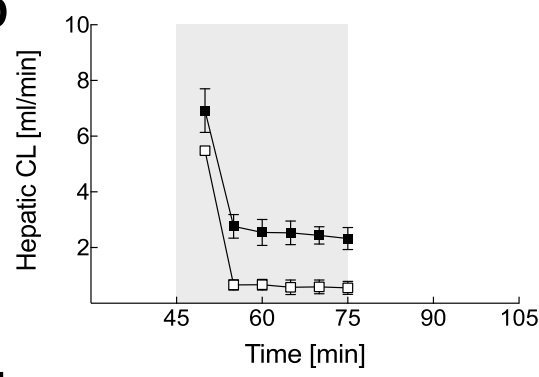

E

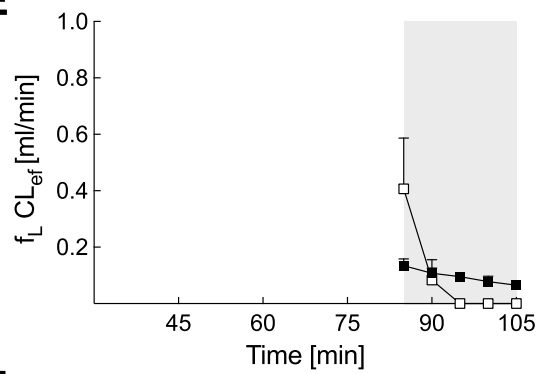

F

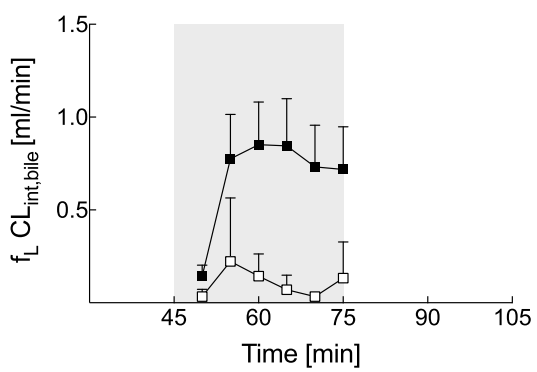

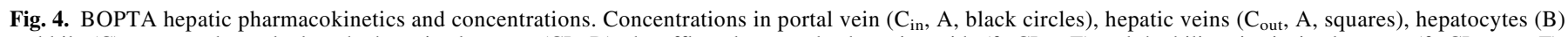

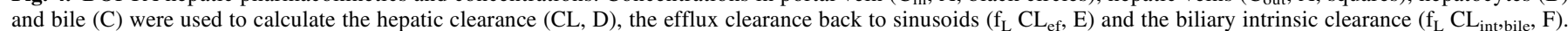

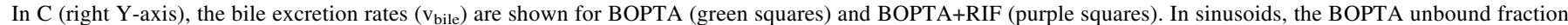

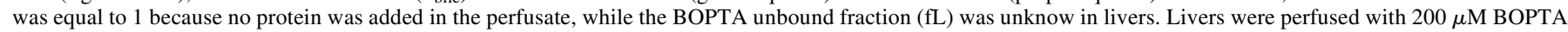

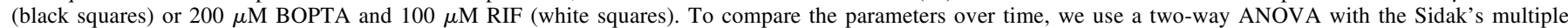
comparison test of mean values at each time-point between groups.

During RIF perfusion, the MEB $\mathrm{v}_{\text {bile }}$ was blocked with a recovery along the rinse period (Fig. 3C, left, $y$-axis). The effect of RIF (+RIF/-RIF ratios) (Table 1) was higher for $\mathrm{v}_{\text {bile }}(0.11)$ and $\mathrm{CL}_{\text {int,bile }}$ (0.05) than for v (0.57) and $\mathrm{CL}_{\text {in }}(0.55)$. The effects of RIF on MEB $\mathrm{f}_{\mathrm{L}} \mathrm{CL}_{\mathrm{ef}}$ were too low to draw a conclusion.

\section{Discussion}

Our study shows that MEB is a promising imaging probe substrate to reveal the transporter-mediated drug-drug interactions when inhibitors such as RIF act on influx and efflux transporters. In the presence of $100 \mu \mathrm{M}$ RIF, the decline of $\mathrm{CL}_{\text {in }}$ depletes hepatocytes from BOPTA at such a low level that Mrp2 inhibition is difficult to detect. The low extraction ratio of BOPTA might be a disadvantage for such preclinical investigations. However, in a similar protocol, we showed previously that the BOPTA hepatocyte uptake increases slightly by decreasing the RIF concentrations from 100 to $1 \mu \mathrm{M}$ (Daali et al., 2013). MEB hepatocyte uptake was decreased moderately in the presence of RIF, and the concomitant Mrp2 inhibition by RIF increased MEB hepatocyte concentrations over time. The hepatocyte concentration-time curve ratios $\mathrm{AUCR}_{\mathrm{HC},+\mathrm{RIF} /-\mathrm{RIF}}$ were divergent (BOPTA, 0.47; MEB, 2). RIF increased $\mathrm{C}_{\text {out }}$ values measured in HVs for both imaging compounds and the $\mathrm{HV}$ concentration-time curve ratios $\mathrm{AUCR}_{\mathrm{Cout},+\mathrm{RIF} /-\mathrm{RIF}}$ increased (BOPTA, 1.07; MEB, 6.43).

In volunteers, MEB was previously injected with the human immunodeficiency virus protease inhibitor ritonavir, which is a substrate and inhibitor of both Oatps and Mrp2 in experimental models (Pfeifer et al., 2013). The MEB systemic concentrations significantly increased while liver and bile concentrations did not change. This study confirms the interest of the imaging probe substrate to investigate transporter-drug-drug interactions in humans. Additional results were obtained with positron emission tomography probe substrates in the presence of RIF (Bauer et al., 2018b; Kaneko et al., 2018). MEB was also used as an imaging probe substrate by Ali et al. (2018) to determine the OATP and MRP2 functions in patients with nonalcoholic fatty liver disease. The liver disease decreases both MEB $\mathrm{CL}_{\text {in }}$ and $\mathrm{CL}_{\text {int,bile }}$ with increased liver and systemic concentrations over time.

Our experimental model also shows that fluxes across transporters generate the hepatocyte concentrations over time. Moreover, it enables an independent quantification of hepatocyte concentrations while Benet et al. (2018b) highlighted recently the difficulty to obtain such values. Consequently, true biliary intrinsic CLs over time were calculated independently of the hepatocyte uptake. These biliary intrinsic CLs were measured over time and by calculating the slopes of the relationship between bile excretion rates and hepatocyte concentrations. BOPTA CLs are higher than MEB CLs, but statistical significance is obtained only when values are measured over time. In the presence of RIF, the MEB biliary intrinsic CL is significantly decreased.

Besides the biliary intrinsic CL, we calculated the basolateral influx and efflux CLs to characterize the rate-limiting step of the systemic CLs. 

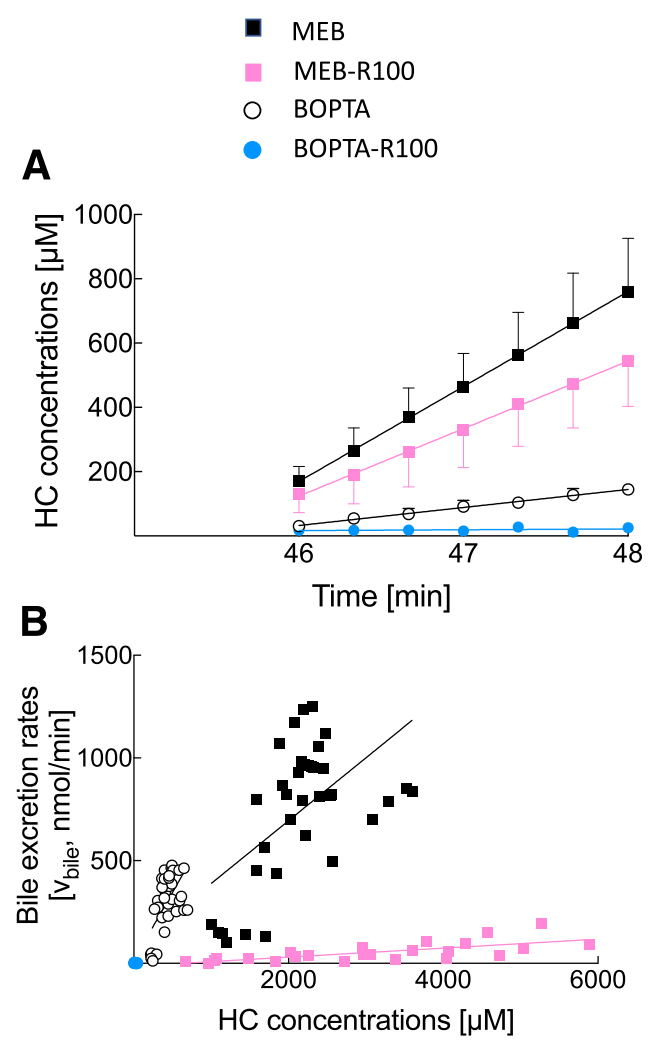

Fig. 5. (A) Using the counter placed over the liver, the hepatocyte uptake into hepatocytes (micromoles per minute) was measured by the slope of the relation between hepatocyte concentrations and time over 2 minutes at the very beginning of the drug perfusion to avoid an underestimation of hepatocyte concentrations associated with early excretion into bile canaliculi. A delay of 1 minute (from 45 to 46 minutes) assured a homogeneous drug distribution within the interstitium. (B) Relationship between bile excretion rates and hepatocyte concentrations. Each symbol illustrates one time point, and six symbols were included by liver (every 5 minutes between 50 and 75 minutes); and the slope of the linear regression

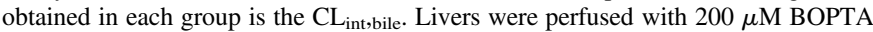
(white circles), $64 \mu \mathrm{M}$ MEB (black squares), $200 \mu \mathrm{M}$ BOPTA and $100 \mu \mathrm{M}$ RIF (blue circles), and $64 \mu \mathrm{M}$ MEB and $100 \mu \mathrm{M}$ RIF (pink squares).

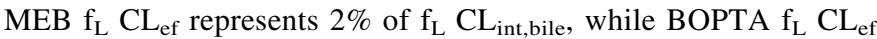
represented $<15 \%$ of $\mathrm{f}_{\mathrm{L}} \mathrm{CL}_{\text {int,bile. Thus, MEB basolateral efflux was }}$ negligible as previously published in human livers (Ghibellini et al., 2008) and only BOPTA increases $\mathrm{C}_{\text {out }}$ with $\mathrm{CL}_{\text {in }}$ values higher than hepatic $\mathrm{CL}$. Consequently, both imaging compounds have $\mathrm{CL}_{\text {in }}>\mathrm{CL}_{\text {int,bile }} \gg \mathrm{CL}_{\mathrm{ef}}$. However, CLs measured over time are not steady. Biliary intrinsic CLs increase at the beginning of the perfusion and rinse periods. This time dependence might be attributed to the changes of perfusion solutions that may induce an inhomogeneous drug distribution within sinusoids. The decreased CLs during the rinse period might be associated with an inhomogeneity of drug concentrations within each hepatocyte where drugs disappear around the sinusoidal membrane while drug concentrations are maintained around the canalicular membrane. The cross talk between both membranes might be lost. However, these comments remain speculative. The hepatic CLs are steady over time for MEB but decrease to a steady state with BOPTA.

Finally, the gradient of bile and hepatocyte concentrations over time quantifies the Mrp2 activity, which is similar for BOPTA and MEB. The parameters decrease greatly in the presence of RIF. Interestingly, these parameters are available in liver imaging (Takashima et al., 2012; Kaneko et al., 2018) and might detect drug-induced liver toxicity in humans.

The isolated and perfused rat liver is a convenient model because the experimental conditions are well controlled and simplified. However, livers are perfused only through the portal vein, avoiding the complexity of a dual-input entry, a condition that can change the physiologic liver perfusion. The imaging compounds we use are free to enter into hepatocytes because the perfused solutions do not contain protein, and $f_{B}$ in perfusate is 1 , but in the bile and liver, the compounds bind to proteins and the counter is unable to discriminate their free and bound fractions. Consequently, except for $\mathrm{CL}_{\text {in }}$ (with $\mathrm{f}_{\mathrm{B}}=1$ ), CLs are expressed as $\mathrm{f}_{\mathrm{L}} \mathrm{CL}_{\mathrm{ef}}$ and $\mathrm{f}_{\mathrm{L}} \mathrm{CL}_{\text {int,bile. The gamma counter placed }}$ over the liver detects the concentrations of both imaging compounds, avoiding the collection of serial liver biopsy samples. Indeed, serial biopsies alter the liver structure over the period of the protocol (Cusin et al., 2017). This improved experimental model directly measures the effects of RIF on fluxes across hepatocyte membranes and is a new tool for the understanding of transporter-mediated drugdrug interactions. We can measure or calculate the concentrations in all liver compartments, except within the interstitium. It describes with precision the drug behavior in rat livers and might validate the data obtained by pharmacokinetic analysis and simulations (Watanabe et al., 2010; Yoshida et al., 2012; Patilea-Vrana and Unadkat, 2016, 2018; Benet et al., 2018a,b).

TABLE 1

BOPTA and MEB pharmacokinetic parameters and concentrations in the presence of RIF (+RIF) and the absence of RIF (-RIF)

\begin{tabular}{|c|c|c|c|c|c|c|}
\hline Parameters & BOPTA & BOPTA+RIF & + RIF/-RIF Ratio & MEB & MEB+RIF & +RIF/-RIF Ratio \\
\hline $\mathrm{C}_{\mathrm{in}}(\mu \mathrm{M})$ & 200 & 200 & & 64 & 64 & \\
\hline $\mathrm{C}_{\text {out }, 75 \min }(\mu \mathrm{M})$ & $185 \pm 3$ & $196 \pm 2$ & 1.06 & $5 \pm 2$ & $31 \pm 4$ & 6.2 \\
\hline $\mathrm{C}_{\mathrm{HC}, 75 \min }(\mu \mathrm{M})$ & $566 \pm 99$ & $23 \pm 19$ & 0.04 & $2611 \pm 498$ & $5044 \pm 693$ & 1.93 \\
\hline $\mathrm{C}_{\text {bile, } 75 \min }(\mu \mathrm{M})$ & $16,791 \pm 2085$ & $92 \pm 44$ & 0.0005 & $97,017 \pm 11,289$ & $13,258 \pm 8363$ & 0.14 \\
\hline $\mathrm{C}_{\text {bile, } 75 \mathrm{~min}} / \mathrm{C}_{\mathrm{HC}, 75 \mathrm{~min}}$ & $30.6 \pm 7.5$ & $3.5 \pm 2.9$ & 0.11 & $38.4 \pm 8.8$ & $2.6 \pm 1.6$ & 0.07 \\
\hline $\mathrm{v}_{75 \mathrm{~min}}(\mathrm{nmol} / \mathrm{min})^{a}$ & $464 \pm 80$ & $111 \pm 47$ & 0.24 & $1797 \pm 61$ & $1022 \pm 113$ & 0.57 \\
\hline $\mathrm{CL}(\mathrm{ml} / \mathrm{min})^{b}$ & $2.32 \pm 0.40$ & $0.56 \pm 0.24$ & 0.24 & $28.12 \pm 0.22$ & $15.64 \pm 1.77$ & 0.56 \\
\hline $\mathrm{E}^{c}$ & $0.08 \pm 0.01$ & $0.02 \pm 0.01$ & 0.25 & $0.93 \pm 0.03$ & $0.53 \pm 0.06$ & 0.57 \\
\hline $\mathrm{v}_{\text {bile }, 75 \min }(\mathrm{nmol} / \mathrm{min})^{d}$ & $390 \pm 84$ & $1 \pm 1$ & 0.003 & $990 \pm 166$ & $105 \pm 65$ & 0.11 \\
\hline $\mathrm{f}_{\mathrm{L}} \mathrm{CL}_{\text {int,bile }}(\mathrm{ml} / \mathrm{min})^{e}$ & $0.72 \pm 0.23$ & $0.04 \pm 0.03$ & 0.06 & $0.39 \pm 0.11$ & $0.02 \pm 0.01$ & 0.05 \\
\hline $\mathrm{f}_{\mathrm{L}} \mathrm{CL}_{\mathrm{ef}}(\mathrm{ml} / \mathrm{min})^{f}$ & $0.13-0.07^{g}$ & $0.41-0.00^{g}$ & & $0.01 \pm 0.01$ & $0.01 \pm 0.01$ & \\
\hline $\mathrm{f}_{\mathrm{B}} \mathrm{CL}_{\mathrm{in}}(\mathrm{ml} / \mathrm{min})$ & $2.69 \pm 0.37$ & $0.60 \pm 0.20$ & 0.22 & $28.54 \pm 0.27$ & $15.64 \pm 1.77$ & 0.55 \\
\hline
\end{tabular}

${ }^{a}$ Drug removal rate from sinusoids $(\mathrm{v})=\mathrm{Q}_{\mathrm{H}} \cdot\left(\mathrm{C}_{\mathrm{in}}-\mathrm{C}_{\mathrm{out}}\right)$.

${ }^{b}$ Hepatic CL: $Q_{H} \cdot\left(C_{\text {in }}-C_{\text {out }}\right) / C_{\text {in }}$

${ }^{c}$ Extraction ratio $(\mathrm{E})=\mathrm{C}_{\mathrm{in}}-\mathrm{C}_{\text {out }} / \mathrm{C}_{\text {in }}$

${ }^{d} \mathrm{v}_{\text {bile }}=\mathrm{Q}_{\text {bile }} \cdot \mathrm{C}_{\text {bile }}$.

${ }^{e} \mathrm{CL}_{\text {int,bile }}\left(\mathrm{f}_{\mathrm{L}} \cdot \mathrm{CL}_{\text {int,bile }}\right)=\mathrm{v}_{\text {bile }} / \mathrm{C}_{\mathrm{HC}}$

${ }^{f} \mathrm{CL}_{\mathrm{ef}}$ back to sinusoids $\left(\mathrm{f}_{\mathrm{L}} \cdot \mathrm{CL}_{\mathrm{ef}}\right)=\mathrm{v}_{\mathrm{ef}} / \mathrm{C}_{\mathrm{HC}}$, with $\mathrm{v}_{\mathrm{ef}}=\mathrm{Q}_{\mathrm{H}} \cdot \mathrm{C}_{\text {out }}$

${ }^{g}$ Mean ranges over time. 


\section{Authorship Contributions}

Participated in research design: Bonnaventure, Pastor.

Conducted experiments: Bonnaventure, Cusin.

Performed data analysis: Bonnaventure, Cusin, Pastor.

Wrote or contributed to the writing of the manuscript: Bonnaventure, Cusin, Pastor.

\section{References}

Ali I, Slizgi JR, Kaullen JD, Ivanovic M, Niemi M, Stewart PW, Barritt AS IV, and Brouwer KLR (2018) Transporter-mediated alterations in patients with NASH increase systemic and hepatic exposure to an OATP and MRP2 substrate. Clin Pharmacol Ther 104:749-756.

Bauer M, Matsuda A, Wulkersdorfer B, Philippe C, Traxl A, Özvegy-Laczka C, Stanek J, Nics L, Klebermass EM, Poschner S, et al. (2018a) Influence of OATPs on hepatic disposition of erlotinib measured with positron emission tomography. Clin Pharmacol Ther 104:139-147.

Bauer M, Traxl A, Matsuda A, Karch R, Philippe C, Nics L, Klebermass EM, Wulkersdorfer B, Weber M, Poschner S, et al. (2018b) Effect of rifampicin on the distribution of $\left[{ }^{11} \mathrm{C}\right]$ erlotinib to the liver, a translational PET study in humans and in mice. Mol Pharm 15:4589-4598.

Belzer M, Morales M, Jagadish B, Mash EA, and Wright SH (2013) Substrate-dependent ligand inhibition of the human organic cation transporter OCT2. J Pharmacol Exp Ther 346:300-310

Benet LZ, Bowman CM, Liu S, and Sodhi JK (2018a) The Extended Clearance concept following oral and intravenous dosing: theory and critical analyses. Pharm Res 35:242.

Benet LZ, Liu S, and Wolfe AR (2018b) The universally unrecognized assumption in predicting drug clearance and organ extraction ratio. Clin Pharmacol Ther 103:521-525.

Bessems M, 't Hart NA, Tolba R, Doorschodt BM, Leuvenink HG, Ploeg RJ, Minor T, and van Gulik TM (2006) The isolated perfused rat liver: standardization of a time-honoured model. Lab Anim 40:236-246.

Blouin A, Bolender RP, and Weibel ER (1977) Distribution of organelles and membranes between hepatocytes and nonhepatocytes in the rat liver parenchyma. A stereological study. J Cell Biol 72:441-455

Bonnaventure P and Pastor CM (2014) Quantification of drug transport function across the multiple resistance-associated protein 2 (Mrp2) in rat livers. Int J Mol Sci 16:135-147.

Caillé F, Goutal S, Marie S, Auvity S, Cisternino S, Kuhnast B, Pottier G, and Tournier N (2018) Positron emission tomography imaging reveals an importance of saturable liver uptake transport for the pharmacokinetics of metoclopramide. Contrast Media Mol Imaging 2018:7310146.

Chu X, Korzekwa K, Elsby R, Fenner K, Galetin A, Lai Y, Matsson P, Moss A, Nagar S, Rosania GR, et al.; International Transporter Consortium (2013) Intracellular drug concentrations and transporters: measurement, modeling, and implications for the liver. Clin Pharmacol Ther 94:126-141.

Cusin F, Fernandes Azevedo L, Bonnaventure P, Desmeules J, Daali Y, and Pastor CM (2017) Hepatocyte concentrations of Indocyanine Green reflect transfer rates across membrane transporters. Basic Clin Pharmacol Toxicol 120:171-178

Daali Y, Millet P, Dayer P, and Pastor CM (2013) Evidence of drug-drug interactions through uptake and efflux transport systems in rat hepatocytes: implications for cellular concentrations of competing drugs. Drug Metab Dispos 41:1548-1556.

Daire JL, Leporq B, Vilgrain V, Van Beers BE, Schmidt S, and Pastor CM (2017) Liver perfusion modifies Gd-DTPA and Gd-BOPTA hepatocyte concentrations through transfer clearances across sinusoidal membranes. Eur J Drug Metab Pharmacokinet 42:657-667.

de Graaf W, Häusler S, Heger M, van Ginhoven TM, van Cappellen G, Bennink RJ, Kullak-Ublick GA, Hesselmann R, van Gulik TM, and Stieger B (2011) Transporters involved in the hepatic uptake of (99m)Tc-mebrofenin and indocyanine green. J Hepatol 54:738-745.

Dollery CT (2013) Intracellular drug concentrations. Clin Pharmacol Ther 93:263-266.

Ghibellini G, Leslie EM, Pollack GM, and Brouwer KL (2008) Use of tc-99m mebrofenin as a clinical probe to assess altered hepatobiliary transport: integration of in vitro, pharmacokinetic modeling, and simulation studies. Pharm Res 25:1851-1860.

Guo Y, Chu X, Parrott NJ, Brouwer KLR, Hsu V, Nagar S, Matsson P, Sharma P, Snoeys J, Sugiyama Y, et al.; International Transporter Consortium (2018) Advancing predictions of tissue and intracellular drug concentrations using in vitro, imaging and physiologically based pharmacokinetic modeling approaches. Clin Pharmacol Ther 104:865-889.

Izumi S, Nozaki Y, Maeda K, Komori T, Takenaka O, Kusuhara H, and Sugiyama Y (2015) Investigation of the impact of substrate selection on in vitro organic anion transporting polypeptide 1B1 inhibition profiles for the prediction of drug-drug interactions. Drug Metab Dispos 43:235-247.
Kaneko K, Tanaka M, Ishii A, Katayama Y, Nakaoka T, Irie S, Kawahata H, Yamanaga T, Wada Y, Miyake T, et al. (2018) A clinical quantitative evaluation of hepatobiliary transport of $\left[{ }^{11} \mathrm{C}\right]$ dehydropravastatin in humans using positron emission tomography. Drug Metab Dispos 46:719-728.

Karlgren M, Vildhede A, Norinder U, Wisniewski JR, Kimoto E, Lai Y, Haglund U, and Artursson P (2012) Classification of inhibitors of hepatic organic anion transporting polypeptides (OATPs): influence of protein expression on drug-drug interactions. J Med Chem 55:4740-4763.

Koide H, Tsujimoto M, Takeuchi A, Tanaka M, Ikegami Y, Tagami M, Abe S, Hashimoto M, Minegaki T, and Nishiguchi K (2018) Substrate-dependent effects of molecular-targeted anticancer agents on activity of organic anion transporting polypeptide 1B1. Xenobiotica 48 $1059-1071$.

Langer O (2016) Use of PET imaging to evaluate transporter-mediated drug-drug interactions. J Clin Pharmacol 56 (Suppl 7):S143-S156.

Leporq B, Daire JL, Pastor CM, Deltenre P, Sempoux C, Schmidt S, and Van Beers BE (2018) Quantification of hepatic perfusion and hepatocyte function with dynamic gadoxetic acid-enhanced MRI in patients with chronic liver disease. Clin Sci (Lond) 132:813-824.

Martínez-Guerrero LJ and Wright SH (2013) Substrate-dependent inhibition of human MATE1 by cationic ionic liquids. J Pharmacol Exp Ther 346:495-503.

Millet P, Moulin M, Stieger B, Daali Y, and Pastor CM (2011) How organic anions accumulate in hepatocytes lacking Mrp2: evidence in rat liver. J Pharmacol Exp Ther 336:624-632.

Mischinger HJ, Walsh TR, Liu T, Rao PN, Rubin R, Nakamura K, Todo S, and Starzl TE (1992) An improved technique for isolated perfusion of rat livers and an evaluation of perfusates. J Surg Res 53:158-165.

Neyt S, Huisman MT, Vanhove C, De Man H, Vliegen M, Moerman L, Dumolyn C, Mannens G, and De Vos F (2013) In vivo visualization and quantification of (Disturbed) Oatp-mediated hepatic uptake and Mrp2-mediated biliary excretion of 99mTc-mebrofenin in mice. J Nucl Med 54:624-630.

Pastor CM, Morel DR, and Billiar TR (1998) Oxygen supply dependence of urea production in the isolated perfused rat liver. Am J Respir Crit Care Med 157:796-802.

Patilea-Vrana G and Unadkat JD (2016) Transport vs. metabolism: what determines the pharmacokinetics and pharmacodynamics of drugs? Insights from the Extended Clearance Model. Clin Pharmacol Ther 100:413-418.

Patilea-Vrana GI and Unadkat JD (2018) When does the rate-determining step in the hepatic clearance of a drug switch from sinusoidal uptake to all hepatobiliary clearances? Implications for predicting drug-drug interactions. Drug Metab Dispos 46:1487-1496.

Pedersen JM, Khan EK, Bergström CAS, Palm J, Hoogstraate J, and Artursson P (2017) Substrate and method dependent inhibition of three ABC-transporters (MDR1, BCRP, and MRP2). Eur J Pharm Sci 103:70-76.

Pfeifer ND, Goss SL, Swift B, Ghibellini G, Ivanovic M, Heizer WD, Gangarosa LM, and Brouwer KL (2013) Effect of ritonavir on (99m)Technetium-mebrofenin disposition in humans: a semiPBPK modeling and in vitro approach to predict transporter-mediated DDIs. CPT Pharmacometrics Syst Pharmacol 2:e20.

Planchamp C, Hadengue A, Stieger B, Bourquin J, Vonlaufen A, Frossard JL, Quadri R, Becke CD, and Pastor CM (2007) Function of both sinusoidal and canalicular transporters controls the concentration of organic anions within hepatocytes. Mol Pharmacol 71:1089-1097.

Swift B, Yue W, and Brouwer KL (2010) Evaluation of (99m)technetium-mebrofenin and (99m)technetium-sestamibi as specific probes for hepatic transport protein function in rat and human hepatocytes. Pharm Res 27:1987-1998.

Takashima T, Kitamura S, Wada Y, Tanaka M, Shigihara Y, Ishii H, Ijuin R, Shiomi S, Nakae T, Watanabe Y, et al. (2012) PET imaging-based evaluation of hepatobiliary transport in humans with (15R)-11C-TIC-Me. J Nucl Med 53:741-748.

Tirona RG, Leake BF, Wolkoff AW, and Kim RB (2003) Human organic anion transporting polypeptide-C (SLC21A6) is a major determinant of rifampin-mediated pregnane $\mathrm{X}$ receptor activation. J Pharmacol Exp Ther 304:223-228.

Tournier N, Stieger B, and Langer O (2018) Imaging techniques to study drug transporter function in vivo. Pharmacol Ther 189:104-122.

Watanabe T, Kusuhara H, and Sugiyama Y (2010) Application of physiologically based pharmacokinetic modeling and clearance concept to drugs showing transporter-mediated distribution and clearance in humans. J Pharmacokinet Pharmacodyn 37:575-590.

Yoshida K, Maeda K, and Sugiyama Y (2012) Transporter-mediated drug-drug interactions involving OATP substrates: predictions based on in vitro inhibition studies. Clin Pharmacol Ther 91:1053-1064.

Address correspondence to: Dr. Catherine M. Pastor, Department of Radiology, Hôpitaux Universitaires de Genève, Rue Gabrielle-Perret-Gentil, 4, 1205 Geneva, Switzerland. E-mail: catherine.pastor@unige.ch 